\title{
Prospek Kopi Pilozz Di Desa Bocek Kecamatan Karangploso Kabupaten Malang
}

\author{
Eko Marhaeniyanto ${ }^{1}$, Sugeng Rusmiwari ${ }^{2}$, Sri Susanti ${ }^{3}$ \\ 1,3 Jurusan Peternakan, ${ }^{2}$ Jurusan Fisip \\ ${ }^{1,3}$ Fakultas Pertanian, ${ }^{2}$ Fakultas Ilmu Sosial dan Politik \\ ${ }^{1,2,3}$ Universitas Tribhuwana Tunggadewi \\ e-mail1'marhaeniyanto@unitri.ac.id, ${ }^{2}$ sugengrusmiwari@yahoo.co.id, ${ }^{3}$ susanti0369@gmail.com
}

\begin{abstract}
Abstrak
Usaha Kopi Pilozz produksi UMKM di Desa Bocek Karangploso dipimpin Ibu Ir. Chresna Cutha Radtra. Keberadaan kopi Pilozz sangat diharapkan petani karena dapat menyerap pemasaran kopi dan meningkatkan produksi kopi lokal. Program kemitraan masyarakat (PKM) bertujuan untuk memberikan dukungan terhadap mitra kopi Pilozz sehingga mampu menjadi UMKM produktif. Usaha Kopi Pilozz memiliki potensi besar untuk bisa dikembangkan namun masih memiliki beberapa kendala. Sarana produksi yang masih sederhana, kemampuan produksi terbatas $(2,5-3 \mathrm{~kg} / \mathrm{hari})$, serta biji kopi yang dihasilkan masih banyak pecah merupakan permasalahan mitra yang perlu dibantu penyelesaiannya. Hasil diskusi dengan mitra diputuskan beberapa program prioritas yaitu pembenahan sarana dan prasarana guna peningkatan kualitas dan kuantitas produksi. Pembuatan dome, peningkatan kapasitas mesin pemecah kulit ari (huller) dan daya mesin penggeraknya, pelatihan dan pendampingan manajemen, menyusun SOP dan SSOP produksi kopi Pilozz hingga memperoleh PIRT, merk dagang kopi Pilozz dan pemasaran secara online merupakan program yang diselesaikan. Melalui pendampingan dari tim PKM maka usaha Kopi Pilozz semakin berkembang, terdapat peningkatan produksi, perbaikan manajemen usaha dan perluasan jaringan pemasaran baik melalui pola kerjasama ataupun pemasaran secara online. Dengan kemasan yang lebih menarik dan mampu menambah masa simpan produk, maka peluang usaha Kopi Pilozz lebih produktif bisa terwujud.
\end{abstract}

Kata kunci : kopi Pilozz; promosi; produksi; pemasaran

\begin{abstract}
Pilozz coffee produced by UMKM led by Ms. Ir. Chresna Cutha Radtra in Bocek Village Karangploso Malang. The existence of the Pilozz coffee was expected by farmers, because it can absorb the coffee marketing and increase local coffee production. The community partnership program (PKM) aims to provide support for Pilozz coffee so that it can become productive UMKM. Pilozz Coffee Business has great potential to be developed, but still have some problems. Production facilities were still simple, limited production capacity (2.5-3 kg/day), and many broken coffee beans were problems that need to be resolved. The results of discussions with partners were decided on several priority programs, that is improving facilities and infrastructure to increase the product quality and quantity. Manufacturing dome, increasing the capacity of the huller and the engine power, training and mentoring management, SOP and SSOP, to obtain PIRT, Pilozz coffee trademarks and online marketing were programs implemented.With assistance from the PKM team, the Pilozz Coffee business was growing, there is an increase in production, improvement in business management and expansion of network marketing through collaboration or online marketing.With more attractive packaging and able to increase product shelf life, the more productive Coffee Pilozz business opportunity can be realized.
\end{abstract}

Keywords : coffee Pilozz; promotion; production; marketing 


\section{PENDAHULUAN}

Kopi sebagai minuman yang popular didunia memiliki kandungan kafein, asam klorogenat serta polifenol lain. Disamping itu juga mengandung asam nikotinat dan zat zat mineral. Kandungan zat tersebut turut mempengaruhi metabolime tubuh manusia, ada yang bersifat positif maupun negatip[1]. Kopi berdampak positip apabila dikonsumsi secara bijak dan tidak berlebihan.Harward Women's Health merekomendasikan mengkonsumsi kopi beberapa cangkir kopi dalam sehari dapat mengurangi resiko diabetes tipe 2, yaitu berkurangnya pembentukan batu ginjal, penyakit Parkinson, kanker usus bersar, penyakit jantung, kerusakan fungsi hati (sirosis) serta dapat menghambat menurunnya daya kognitif otak [1].

Pada sub sektor perkebunan, tanaman kopi turut menyumbangkan devisa cukup besar [2]. Tanaman kopi yang ditanami oleh masyarakat Desa Bocek dan Desa Tawangargo Kecamatan Karangploso Kabupaten Malang merupakan lahan milik Perhutani dengan luasan 2000 Ha serta lahan milik Universitas Brawijaya dengan luas $554 \mathrm{Ha}$. Jenis kopi yang ditanam didominasi jenis Robusta dan Arabika seluas $750 \mathrm{Ha}$, dengan populasi 22.500.000 tanaman. Kemampuan produksi kopi ratarata 2 ton/ha/musim panen. Melihat potensi tersebut, maka para pemuda setempat yang tergabung dalam kelompok tani berusaha untuk mendapat dukungan pihak Pemerintah Desa Bocek yang diwujudkan dalam Wisata Petik Kopi dan Jeruk Keprok. Beberapa program seperti pembangunan "kedai kopi" di lahan bengkok desa dekat balai desa telah didirikan sebagai sarana untuk market hasil olahan kopi. Produk yang dipasarkan saat ini berupa kopi sangrai jenis Robusta dan Arabika, kopi bubuk dengan penyajian yang sederhana. Namun dengan terbatasnya pengetahuan, keterampilan dan kesempatan untuk mencurahkan serta mengembangkan potensi yang ada di desa maupun di sekeliling desa, masih membutuhkan tenaga yang berpengalaman. Untuk itu perlu upaya pemberdayaan masyarakat. Pemberdayaan mempunyai tujuan yang sama, yaitu untuk membangun daya dan mendorong, memotifasi dan membangkitkan kesadaran akan potensi yang dimilikainya serta upaya untuk mengembangkannya [3]. Dalam kerangka pemberdayaan ini [4] dan [5] mengemukakan 2 (dua) hal yakni:

1. Menciptakan suasana atau iklim yang memungkinkan potensi masyarakat berkembang (enabling) dengan titik pandang bahwa setiap manusia (masyarakat) memilki potensi. Dengan menciptakan iklim yang kondusif, maka potensi masyarakat dapat berkembang dengan memberikan dorongan, motivasi dan membangkitkan kesadaran masyarakat akan potensi yang dimilikinya.

2. Memperkuat potensi (empowering) dengan langkahlangkah konkrit yang menyangkut penyediaan berbagai masukan (input) dan pembukaan (askes) ke dalam berbagai kesempatan (opportunities) yang akan membuat masyarakat semakin berdaya.

Program Kemitraan Masyarakat (PKM) yang bermitra dengan pemilik kopi Pilozz termasuk dalam kategori Mitra yang mengarah ke ekonomi produktif. Usahakopi Pilozz memiliki prospek yang baik, didukung dekat dengan petani kopi. Produk kopi Pilozz diproduksi dengan tahapan pemilihan kopi yang baik (matang fisiologis), penyortiran dari ranting, daun, dan kopi yang telah busuk, penggradingan terhadap tingkat kemasakan dan ukuran, pengeringan dengan penjemuran, pengupasan kulit, penyangraian, pengecilan ukuran dan penepungan, dan pengemasan [6]. Mitra pemilik kopi Pilozz selama ini menerima kopi merah gelondong dari petani. Petani kopi dalam memanen kopi masih belum memisahkan kopi gelondong merah dan kopi yang masih hijau, sehingga kualitas kopi bila tidak dilakukan seleksi, kualitas kopi yang dihasilkan tidak terkontrol. Mitra kopi Pilozz hanya menerima kopi dari petani gelondong merah dengan jumlah pembelian 1-2 kuintal/periode panen. Kopi gelondong merah yang sudah dibeli, dilakukan proses sortir biji gelondong dengan melakukan pencelupan kopi ke dalam bak air.Kopi yang terapung disortir. Pada proses grading/sortir dan pencucian ada 4 alternatip yang bias dilakukan: (1). Kopi merah gelondong yang masih ada kulitnya langsung dijemur 
(proses natural); (2). Kopi langsung di pulper tanpa di cuci kemudian dijemur (proses honey); (3). Kopi gelondong dipulper kemudian dijemur (proses semiwash); (4). Kopi gelondong di pulper, kemudian di cuci terus direndam minimal 36 jam (proses fullwash). Aktifitas selanjutnya dilakukan proses pecah kulit kopi (pulper). Biji yang sudah terkelupas kemudian di cuci dan direndam selama 36 jam, baru kemudian kopi di jemur. Terdapat permasalahan didalam proses penjemuran, karena belum memiliki dome yang tertutup, sehingga dalam usulan kegiatan PKM ini salah satu kesepakatannya untuk mengoptimalkan proses pengeringan supaya lebih higienis dan berkesinambungan dengan menyempurnakan dome untuk penjemuran dengan bahan bambu, kayu dan tertutup plastik.

Proses penjemuran yang sudah dilakukan selama ini berkisar 3-4 hari apabila musim panas, di bawah sinar matahari langsung. Umumnya proses ini dilakukan selama 5-7 hari sampai kadar air yang terkandung di dalam biji kopi tersisa sekitar 30-35\%. Biji-biji yang telah mengering sempuran ini kemudian dipindahkan ke penggorengan untuk dimasak/disangrai ${ }^{7}$.

Kopi yang sudah kering selanjutnya dilakukan proses huller (pecah kulit ari). Permasalahan utama dari mitra kopi Pilozz adalah dalam proses huller, masih didapati selama proses pecah kulit ari, kopi tidak sempurna terkelupas kulit arinya dan kopi pecah. Alat huller yang dimiliki berkapasitas kecil dan tenaga mesinnya juga kecil, sehingga dirasa kurang maksimal dan banyak biji kopi yang pecah. Selama ini kapasitas huller hanya mampu menyelesaikan dengan produksi $15 \mathrm{~kg} /$ setiap prosesing, dan setiap hari hanya membuat bubuk 2,5-3 $\mathrm{kg}$ /hari. Hasil diskusi dengan mitra kopi Pilozz apabila dapat ditingkatkan kapasitas huller dan daya mesin penggeraknya diyakini akan mampu meningkatkan produksi dan kualitas kopi yang dihasilkan. Dukungan terhadap mitra kopi Pilozzdalam kegiatan PKM ini diharapkan mampu mewujudkan mitra menjadi UMKM produktif.
Biji-biji yang telah mengering sempuran ini setelah penjemuran, di huller, kemudian dilakukan sortir biji, kemudian dipindahkan ke penggorengan (roasting) untuk dimasak/disangrai [7]. Selama proses penggorengan, bijibiji kopi harus dibolak-balik secara rutin agar tidak gosong. Biji kopi digoreng sampai permukannya berubah warna menjadi cokelat kelam, aroma khasnya semakin keluar, dan mudah dihancurkan. Sebagai gambaran, proses penggorengan $2 \mathrm{~kg}$ biji kopi umumnya memakan waktu selama 2 jam.

Biji kopi yang telah disangrai hingga matang sempurna kemudian digiling sampai halus. Setelah itu, bubuk kopi ini diayak untuk memisahkan partikel yang masih berukuran cukup besar. Bubuk kopi hasil penggilingan ini disimpan di dalam wadah yang bersih, kering, dan tertutup rapat sehingga kenikmatannya tetap terjaga.

Keseluruhan tahapan proses tersebut harus dilakukan secara hygienis agar kontaminasi mikroba dapat dihindari. Demikian pula pada tahapan khusus yang merupakan titik kendali kritis seperti penyangraian dan pencampuran bahan perlu dilakukan kontrol. Faktor pendukung seperti jenis dan desain kemasan perlu diperhatikan agar produk tetap terjaga kualitasnya dengan masa simpan yang relatif lama.

\section{SUMBER INSPIRASI}

Berdasarkan analisis situasi beberapa permasalahan yang teridentifikasi di mitra kopi Pilozz adalah sebagai berikut :

1. Sarana produksi yang masih sederhana perlu mendapat stimulasi dari program PKM dan sangat memerlukan Dome untuk penjemuran kopi, sehingga kapasitas untuk menghasilkan produksi kopi bubuk yang berkualitas sangat terbuka.

2. Untuk mengurangi kopi yang rusak/ pecah selama proses huller, disepakati diusulkan adanya peningkatan kapasitas dan daya mesin huller.

3. Manajemen produksi yang diterapkan belum menunjang pengembangan produksi yang lebih besar, misalnya belum menerapkan SSOP, belum 
mempunyai Standard Operating Procedures (SOP), sehingga untuk menghasilkan kekhasan kopi bubuk Pilozzsangat penting perbaikan manajemen produksi.

4. Produk kopi yang dihasilkan perlu merk dagang dengan nama kopi Pilozz dan diurus PIRT nya.

5. Pemasaran produk belum dikembangkan lebih luas sehingga diperlukan pembuatan media promosi secara on line.

Solusi yang ditawarkan kepada mitra sebagai berikut:

1. Pembenahan sarana dan prasarana dalam upaya peningkatan kualitas dan kuantitas produksi dengan menyiapkan dome penjemuaran kopi dengan bahan dari bambu, supaya bersih dan plastik U.V.

2. Peningkatan kapasitas huller dan daya mesin penggeraknya dengan spesifikasi bahan rangka dan body Carbon steel, Dimensi keseluruhan (PxLxT): 65 x 22 x $110 \mathrm{~cm}$; Motor penggerak Engine Bensin Robin ET20-3D (5,0 Hp); Corong pengumpanan (hopper) (PxLxT) ; 32 × 32 × 32 cm; Kapasitas ; $300 \mathrm{~kg} / \mathrm{jam}$ dan berat mesin $50 \mathrm{~kg}$

3. Pelatihan dan pendampingan pengembangan manajemen dengan membuat SOP dan SSOP produksi kopi Pilozz.

4. Pendampingan terhadap mitra untuk mendapatkan merk dagang PIRT kopi Pilozz

5. Bimbingan pemasaran secara online dan desain kemasan primer untuk memperpanjang umur simpan kopi, untuk itu diperlukan diversifikasi ukuran kemasan, dan sealer untuk menunjang kualitas kemasan supaya terjaga mutunya [8]

Hasil kegiatan PKM di mitra kopi Pilozz disampaikan pada forum yang lebih luas di Balai desa Bocek Kecamatan Karangploso dengan menghadirkan perwakilan masyarakat diantaranya Karang taruna, PKK, aparat desa, ketua RT, Ketua RW, serta Dinas Pertanian Kabupaten Malang. Selama pelaksanaan kegiatan berlangsung, tim PKM mengundang media massa, sehingga hasilnya dapat dipublikasikan di media cetak (Koran)/elektronik radio. Luaran wajib dari kegiatan
PKM Kopi Pilozz meliputi: naskah out put kegiatan PKM turut serta sebagai pemateri pada seminar nasional, dipublikasikan di Jurnal nasional Pengabdian Masyarakat, peningkatan produksi kopi Pilozz dan pengembangan inovatif produk, perbaikan manajemen pada mitra, SOP dan SSOP. Luaran tambahan berupa: (1) HKI buku praktis bisnis Kopi Pilozz(2) Buku praktis ber ISBN tentang “ Bisnis Kopi Pilozz Khas Malang” (3) PIRT dan (4) Merk Dagang.

Melalui kegiatan PKM ini peningkatan produksi kopi bubuk tradisional khas Malang dengan biaya produksi lebih efisien, hygiene product diterapkan, sehingga berdampak pada peningkatan jumlah anggota kelompok Posdaya.

\section{METODE KEGIATAN}

Dalam melaksanakan kegiatan PKM pendekatan yang dilakukan untuk menyelesaikan persoalan mitra merupakan kegiatan yang telah disepakati bersama mitra sehingga target utama dan waktu realisasi program PKM dapat sesuai jadwal yang disepakati.

Metode yang dilakukan oleh Tim PKM dalam melaksanakan solusi dari permasalahan mitra perihal: 1) Pembenahan sarana dome penjemuran, 2) Peningkatan kapasitas huller, 3). Pendampingan penyusunan dan implementasi SOP setelah alih teknologi proses pembuatan kopi bubuk yang baik , 4). Merk dagang dan PIRT serta 5). Promosi on line kopi pilozz, adalah sebagai berikut :

1. Mengumpulkan khalayak sasaran di rumah Ibu Ir. Chresna Cutha Radtra di Jl. Sumbersuko No 1 Desa Bocek Kecamatan Karangploso, Kab. Malang Jawa Timur.untuk diberikan penjelasan tentang rencana kegiatan PKM di mitra. Tujuan metode ini adalah untuk meningkatkan pengetahuan mitra mengenai materi kegiatan. Kegiatan ini dengan diskusi tentang materi kegiatan yang bertujuan untuk tukar pengalaman antara tim penyuluh dengan khalayak sasaran. Khalayak sasaran juga diberi brosur yang berisi tentang materi kegiatan. 
2. Bantuan sarana pendukung sarana dome penjemuran kopi dengan bahan dari bambu, lantai berpaving supaya bersih dan plastic U.V.

3. Bantuan peningkatan kapasitas huller untuk meningkatkan produksi dan meningkatkan kualitas kopi roaster, dan mengurangi kopi pecah (tersortir)

4. Pelatihan dan pendampingan pengembangan manajemen dengan membuat SOP dan SSOP produksi kopi bubuk dan pendampingan pelaksanaannya.

5. Pendampingan pengurusan Merk Dagang Kopi Pilozzdan Pengurusan PIRT di Deperindag Malang

6. Bimbingan pemasaran secara online dan desain kemasan primer untuk memperpanjang umur simpan kopi, untuk itu diperlukan diversifikasi ukuran kemasan, untuk menunjang kualitas kemasan supaya terjaga mutunya.

7. Pelaksanaan kegiatan ini melibatkan mahasiswa untuk turut serta dalam pendampingan dengan tujuan memberi contoh riil dilanjutkan praktek.

Tim pelaksana PKM ini terdiri dari ketua dan satu anggota yang saling bersinergi mendukung pelaksanaan program ini dalam menyelesaikan permasalahan mitra.

\section{KARYA UTAMA}

Berawal dari nama Kopi Alas dalam catatan Dinas Perindustrian dan Perdagangan Malang sudah tercatat pada Maret 2017 produk nama "Kopi Alas" tidak diperkenankan sehingga dari tim produksi disepakati untuk mendaftarkan dengan nama Kopi Pilozz. Pemikiran dan ide dasar nama kopi Pilozz (Kopi Karangploso) yaitu kopi dengan bahan baku dari kopi lokal dari kebun kopi petani di wilayah kecamatan Karangploso.

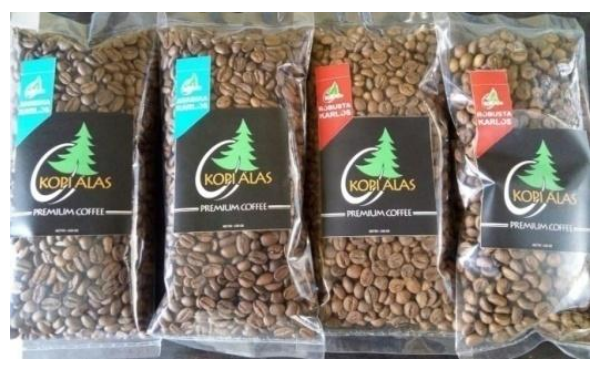

Gambar 1. Pada awalnya produk kopi milik mitra diberi nama "Kopi Alas"

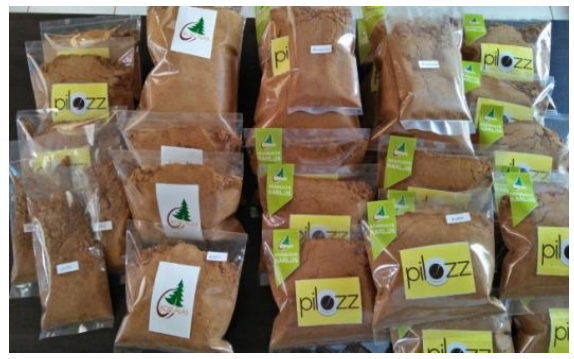

Gambar 2. Kopi milik mitra diberi nama "Kopi Pilozz"

Untuk memaksimalkan usaha kopi Pilozz, tim pelaksana sudah bersepakat dengan mitra untuk bersama sama membenahi sarana pendukung dome penjemuran kopi dengan bahan dari bambu, lantai berpaving supaya bersih dan plastic U.V. Kondisi setelah dilakukan kegiatan, dome yang ada di mitra kopi Pilozz seperti Gambar 3.

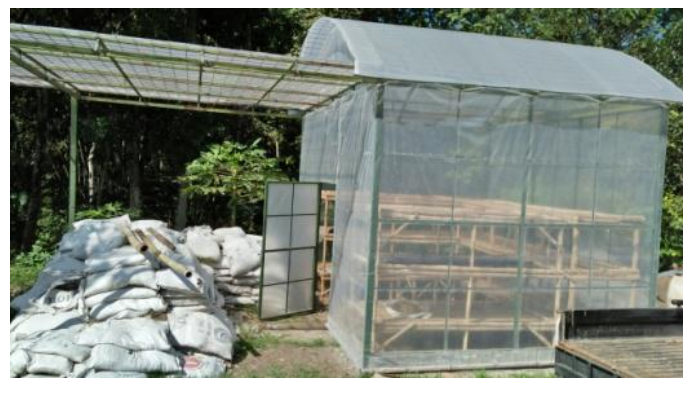

Gambar 3. Dome untuk penjemuran kopi

Kopi Pilozz yang diproduksi mitra memiliki keunggulan dalam prosesing. Secara umum produsen kopi mengolah kopi bubuk dari proses secara natural. Proses natural yaitu suatu proses pengeringan biji kopi yang langsung dijemur di bawah paparan sinar matahari. Kopi yang diproses tanpa adanya proses sortasi awal, dimana petani pada umumnya melakukan pemanenan secara merata/campuran antara biji merah, kuning dan hijau. Sedangkan dari proses pengolahan awal sotasi biji merah, kuning dan bahkan hijau masing-masing memberikan citarasa serta mutu/kualitas bahan yang berbeda.Prosesing kopi Pilozz sebagai berikut :

1). Sortasi Awal : pemilihan biji merah (red cherry)

2). Proses rambang : pemisahan biji bernas dan kopong

3). Penentuan proses lanjutan

a. Proses natural : Biji merah bernas dijemur langsung didalam dome penjemuran yang telah dibuat dengan standart untuk penjemuran kopi, 
sehingga panas diperoleh bisa maksimal dan terlindung dari debu. Kopi yang dihasilkan dari proses kering biasanya unggul dalam body, floral, lebih pahit dan acidity rendah

b. Proses semi wash : Proses olah basah dimana biji yang telah di sortir kemudian di pulper (pengupasan kulit luar). Fermentasi dilakukan selama 24 jam, dilanjutkan dengan pencucian. Setelah hasil cucian bersih, dilakukan penjemuran.

c. Proses full wash : Proses olah basah dimana biji yang telah di sortir kemudian di pulper (pengupasan kulit luar). Fermentasi dilakukan selama 36 - 42 jam dilanjutkan dengan pencucian. Setelah hasil cucian bersih, dilakukan penjemuran. Pada proses olah basah dengan proses fermentasi yang tepat/ tidak over fermented maka kopi yang dihasilkan biasanya unggul dalam tekstur kopi lebih lembut, aroma lebih kuat, body ringan, after taste lebih berkesan, acidity lebih tinggi.

d. Honey Proses : Proses olah basah dimana biji yang telah di sortir kemudian di pulper (pengupasan kulit luar) dilanjutkan dilakukan penjemuran.

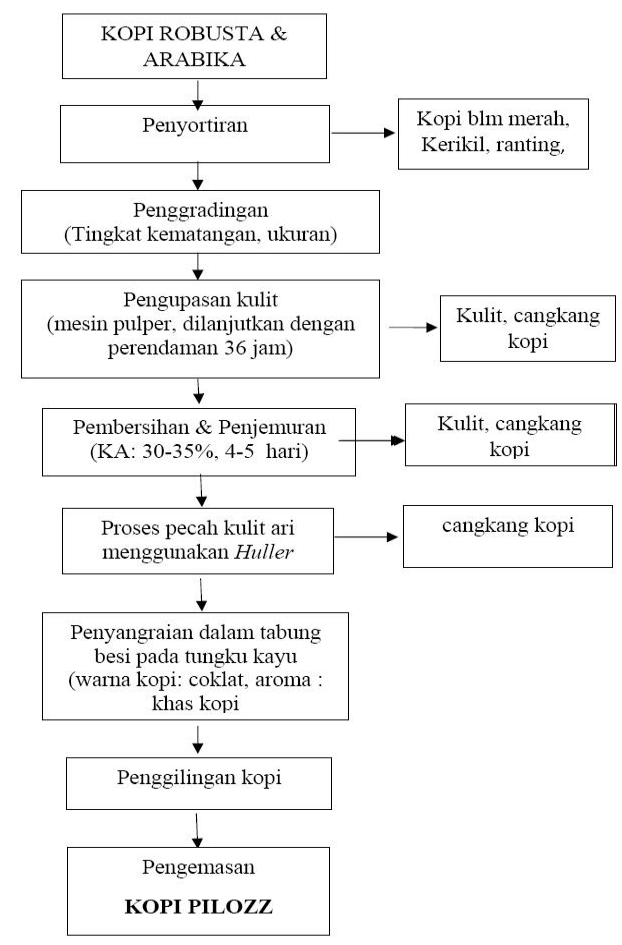

Gambar 4. Diagram alir proses pembuatan kopi Pilozz
Untuk meningkatkan produksi dan meningkatkan kualitas kopi roaster, dan mengurangi kopi pecah (tersortir) tim PKM memberi bantuan peningkatan kapasitas hullerdengan spesifikasi bahan rangka dan body Carbon steel, Dimensi keseluruhan (PxLxT): $65 \mathrm{x}$ 22 x $110 \mathrm{~cm}$; Motor penggerak Engine Bensin Robin ET20-3D (5,0 Hp); Corong pengumpanan (hopper) (PxLxT) ; 32 x 32 x 32 cm; Kapasitas ; 300 kg/jam dan berat mesin $50 \mathrm{~kg}$.

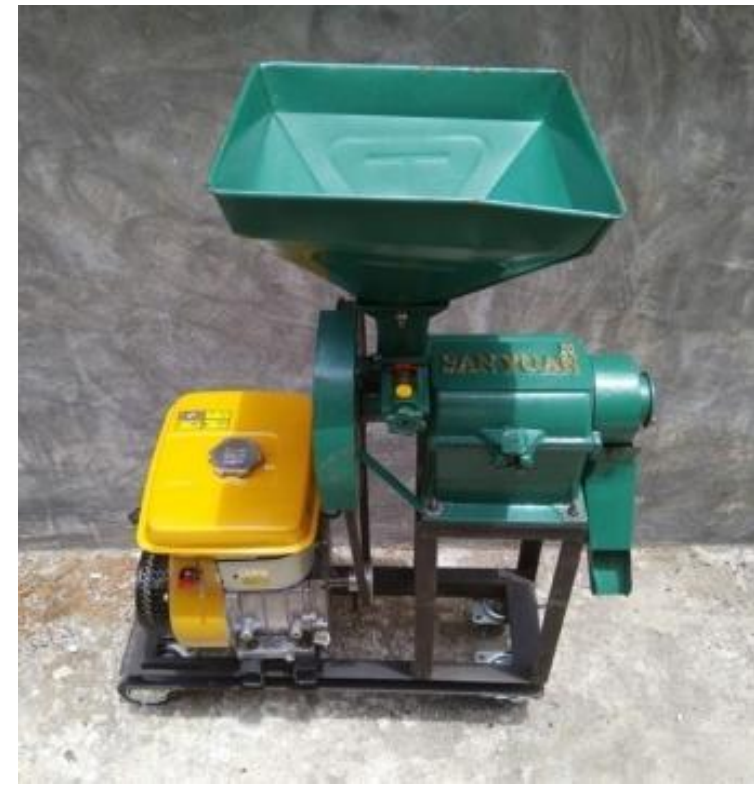

Gambar 5. Mesin huller

Bantuan sarana pendukung dan peralatan sangat dirasakan manfaatnya oleh mitra dalam upaya meningkatkan produksi dan kualitas produk kopi Pilozz.

Secara umum pada sasaran konsumen para pecinta kopi yang mengetahui mutu/kualitas kopi menyatakan bahwa kopi Pilozz patut untuk disajikan sebagai kopi dengan kualitas yang baik. Akan tetapi dari tim kopi Pilozzmasih perlu belajar banyak hal agar mutu kopi yang dihasilkan dapat ditingkatkan dan berproduksi secara kontinu.

Penentuan harga jual kopi berdasarkan perhitungan biaya produksi dan perkembangan harga pasar serta memperhitungkan segmentasi pasar. Tabel 1. menjelaskan perbedaan harga kopi berdasarkan kualitas kopi Pilozz. 
Tabel 1. Harga Produk Kopi Berdasarkan Kualitas Kopi

\begin{tabular}{|c|l|c|c|}
\hline No & \multicolumn{1}{|c|}{ Produk } & $\begin{array}{c}\text { Berat/ } \\
\text { kemasan } \\
\text { (gram) }\end{array}$ & Harga (Rp) \\
\hline \multirow{2}{*}{1} & Robusta & 250 & 30.000 \\
& Premium & 100 & 13.500 \\
& & 50 & 7.500 \\
\hline 2 & Arabica & 250 & 55.000 \\
& Premium & 100 & 24.000 \\
\hline 3 & Robusta Reguler & 200 & 16.000 \\
& & 100 & 8.000 \\
\hline 4 & Arabica Reguler & 200 & 16.000 \\
& & 200 & 16.000 \\
\hline 5 & Kopi Jahe & 100 & 8.000 \\
\hline
\end{tabular}

\section{ULASAN KARYA}

Mitra kopi Pilozz telah memiliki PIRT dan Merk dagang kopi Pilozz. Kelebihan kopi Pilozz dibanding produk kopi lain dikarenakan kopi Pilozz diproduksi dengan mengambil bahan baku kopi dari petani di wilayah kecamatan Karangploso. Secara geografis wilayah kecamatan Karangploso merupakan wilayah lereng gunung Arjuno dengan ketinggian berkisar antara 500 - 1500 mdpl. Produk utama kopi Pilozzberupa kopi bubuk Robusta dan Arabica. Bahan untuk kopi robusta diambil dari petani di desa Bocek dimana ketinggian wilayah desa Bocek berkisar antara 400-800 mdpl. Ketinggian tempat tersebut merupakan salah satu syarat tumbuh optimal kopi robusta, sehingga dengan cara pengolahan/proses yang berstandar serta pemilihan biji kopi melalui petik merah (red cherry) diperoleh mutu dan citarasa kopi yang tetap terjaga. Ketinggian tempat dan topografi wilayah satu tempat dengan tempat yang lain memberikan ciri khas cita rasa yang berbeda, dengan demikian kopi Pilozzmerupakan salah satu produk kopi dengan cita rasa lereng gunung Arjuno yang pasti berbeda dengan cita rasa kopi wilayah lereng Bromo maupun Semeru. Produk sampingan dari sisa biji kopi sortir, diproduksi menjadi produk kopi regular dengan sasaran bidik konsumen yang berbeda dari kopi kualitas premium. Salah satu inovasi tambahan pada produk kopi regular yaitu membuat produk kopi jahe. Proses berbeda dari kopi jahe yang dijual di warung kopi secara umum dimana kopi diseduh dengan geprekan jahe mentah, sedangkan produk kopi jahe Pilozzdiproses dari jahe emprit yang dikeringkan dan disangrai bersama biji kopi kemudian dibuat produk bubuk kopi jahe yang siap seduh.

Mengingat keterbatasan stok bahan baku pada awal produksi, kemampuan produksi per minggu sekitar $30 \mathrm{~kg}$ bahan biji oce.Rencanapengembangan kopi Pilozz ingin mempunyai kedai dan rumah produksi diluar, sehingga tempat tersebut dapat digunakan sebagai tempat menikmati kopi dengan berbagai edukasi yang dapat kita sampaikan kepada konsumen sebagai tambahan wawasan. Jangkauan pemasaran dapat lebih luas melalui pengembangan strategi informasi website khusus kopi Pilozz.

Kendala-kendala lain yang masih dihadapi kopi Pilozz selama kegiatan PKM diantaranya keterbatasan permodalan, alat pemotong jahe masih manual (perlu mesin chopper jahe), alat timbangan masih tradisional (perlutimbangan digital) kapasitas minimal 100kg untuk akurasi pembelian bahan kopi dari petani, Alat roasting masih sederhana belum dilengkapi dengan pengukur suhu dan pengecekan tingkat kematangan biji.

Untuk pengembangan kopi Pilozz, potensipendukunguntukpengembangan diantaranya mendapatkan permodalan baik secara hibah maupun pinjaman modal. Upaya lain yang dilakukan dengan membuka peluang bagi lembaga pendidikan untuk melakukan penelitian/pengabdian kepada masyarakat sehingga output dari kegiatan tersebut terjalin kerjasama yang saling menguntungkan. Ketersediaan bahan baku melimpah (kopi dari wilayah lereng Arjuno dengan luasan sekitar 1500 ha dan produktivitas $4 \mathrm{kw} / \mathrm{ha}$ sangat potensial untuk pengembangan usaha).

Peran kelembagaan yang turut menunjang pengembangan kopi Pilozz berasal dari dinas Pertanian. Dalam rangka mensukseskan salah satu tujuan nasional melalui peningkatan produksi PAJALE (Padi Jagung Kedele) dan KOTEKA (Kopi Tebu Kakao), makasalah satu tugas pokok Penyuluh Pertanian Lapang (PPL) adalah membina, memberikan informasi, edukasi dan merubah sikap perilaku pelaku utama (petani yang tergabung dalam wadah kelompok tani). Melalui potensi di wilayah masing-masing yang dapat diangkat sebagai 
produk unggulan wilayah setempat. Karangploso dengan potensi yang ada termasuk tanaman kopi, selama ini belum tersentuh sehingga petanipun melakukan budidaya secara mandiri dan asal-asalan tanpa perawatan dan petunjuk pemeliharaan kopi yang baik untuk memperoleh produksi yang optimal. Berawal dari permasalahan tersebut menjadi salah satu tujuan mitra yang berprofesi sebagai penyuluh untuk mengangkat komoditas kopi sebagai produk unggulan di wilayah kecamatan Karangploso dengan melakukan pembinaan kepada petani/kelompok tani. Diharapkan kopi Pilozz dikenal masyarakat, khususnya petani dengan system pemeliharaan/budidaya yang baik dapat meningkatkan produksi kopi sehingga pendapatan/ kesejahteraan keluarga dapat meningkat.

Dari pelaksanaan PKM ini dapat memberikan contoh bahwa proses pengolahan yang baik dan benar akan memberikan keuntungan yang lebih besar, sehingga para petani/poktan tergerak untuk mau melakukan proses pengolahan kopi dengan baik dan benar sebagai suatu usaha kelompok.

\section{KESIMPULAN}

UMKM Kopi Pilozz termasuk kategori Mitra yang mengarah ke ekonomi produktif, telah memiliki PIRT dan Merk dagang Pilozz. Usaha kopi Pilozz keberadaannya sangat diharapkan petani kopi di Desa Bocek, dapat menyerap pemasaran dari produksi kopi masyarakat sekitar, juga berperan mendampingi masyarakat dalam meningkatkan produksi kopi. Pelaksanaan PKM di mitra kopi Pilozz menghasilkan peningkatan produksi, perbaikan manajemen usaha dan memperluas jaringan pemasaran baik dengan pola kerjasama dan pemasaran secara on line. Kopi Pilozz memiliki peluang pasar yang baik, terbukti dari kemampuan produksi tiap hari $3 \mathrm{~kg}$ selalu terserap habis. Dengan kemasan yang lebih menarik dan mampu menambah masa simpan produk, maka peluang usaha Kopi Pilozz lebih produktif bisa terwujud.

\section{DAMPAK DAN MANFAAT KEGIATAN}

Kegiatan PKM kopi Pilozz di desa Bocek Kecamatan Karangploso Malang telah melakukan kegiatan-kegiatan yang menghasilkan luaran dan dampak yang diterima mitra seperti pada Tabel 2.

Tabel 2. Bentuk Kegiatan, Luaran, dan Indikator Program PKM yang dihasilkan

\begin{tabular}{|c|c|c|c|}
\hline No. & Bentuk Kegiatan & Luaran & Indikator \\
\hline 1. & $\begin{array}{l}\text { Pembuatan Dome untuk penjemuran } \\
\text { kopi dari bahan bamboo, kayu dan } \\
\text { plastic PVC }\end{array}$ & $\begin{array}{l}\text { Jumlah kopi yang dijemur lebih banyak, dan } \\
\text { bersih, terbebas dari debu kotor dan tidak } \\
\text { berserakan }\end{array}$ & Penanganan dalam penjemuran kopi lebih baik \\
\hline 2. & Meningkatkan kapasitas mesin huller & $\begin{array}{l}\text { Peningkatan produksi kopi bubuk kopi } \\
\text { Pilozzdengan kualitas yang lebih baik, semakin } \\
\text { sedikit kopi yang rusak dan pecah. }\end{array}$ & $\begin{array}{l}\text { Peningkatan kapasitas jumlah produksi dari kapasitas } \\
\text { produksi sebelumnya yang hanya } 2,5-3 \mathrm{~kg} \text { setiap hari ( } 15 \\
\mathrm{~kg} / \text { minggu) produksi menjadi } 5 \mathrm{~kg} / \text { hari }(35-40 \\
\mathrm{kg} / \text { minggu) }\end{array}$ \\
\hline 3. & $\begin{array}{l}\text { Penerapan manajemen sehingga kualitas } \\
\text { produk terjaga konsistensinya, dengan } \\
\text { menghadirkan narasumber yang } \\
\text { kompeten tentang pembuatan kopi }\end{array}$ & $\begin{array}{l}\text { Pembenahan dan pengadaan sarana produksi yang } \\
\text { disesuaikan dengan kondisi lokasi produksi dan } \\
\text { jumlah produksi }\end{array}$ & $\begin{array}{l}\text { Sarana - prasarana sesuai dengan cara berproduksi } \\
\text { kopi bubuk yang baik (CPMB) 50\% terlaksana }\end{array}$ \\
\hline 4. & Pengemasan dan pemasaran & $\begin{array}{l}\text { Pengembangan design kemasan dan pemberian } \\
\text { Labeling sesuai yang diprasyaratkan, serta di } \\
\text { publikasikan secara on line }\end{array}$ & $\begin{array}{l}\text { Label dan kemasan yang disepakati dengan Mitra, serta } \\
\text { Vidio untuk promosi kopi Pilozzsecara on line }\end{array}$ \\
\hline 4. & $\begin{array}{l}\text { Pendampingan penyusunandan } \\
\text { implementasi } \\
\text { StandardOperatingProcedures(SOP) }\end{array}$ & $\begin{array}{l}\text { SOP untuk pemilihan bahan baku } \\
\text { SOP untuk formulasi produk } \\
\text { SOP proses pembuatan } \\
\text { Produk }\end{array}$ & Ada SOP dan impelemtasi SOP \\
\hline 5. & $\begin{array}{l}\text { Pendampingan penerapan SSOP } \\
\text { (Standard Sanitation Operating } \\
\text { Procedure) }\end{array}$ & $\begin{array}{l}\text { SSOP peralatan } \\
\text { SSOP pekerja } \\
\text { SSOP lingkungan }\end{array}$ & Ada SSOP dan implementasi SSOP \\
\hline 6. & $\begin{array}{l}\text { Pendampingan penerapan standart } \\
\text { sanitasi dan hygyene }\end{array}$ & $\begin{array}{l}\text { Panduan sanitasi peralatan } \\
\text { Panduansanitasi lingkungan } \\
\text { Panduan sanitasi pekerja }\end{array}$ & $\begin{array}{l}\text { Ada standart hygiene dan sanitasi serta } \\
\text { diimplementasikan }\end{array}$ \\
\hline 7. & $\begin{array}{l}\text { Pendampingan untuk mendapatkan PIRT } \\
\text { dan Merk dagang }\end{array}$ & PIRT dan Merk dagang kopi Pilozz & Ada PIRT dan ada HKI Merk dagang kopi Pilozz \\
\hline
\end{tabular}


Untuk menjamin keberlanjutan program, monitoring dilakukan secara berkala untuk melihat perkembangan dari kegiatan yang sedang dijalankan serta membantu menyelesaikan permasalahan yang ada dilapangan. Evaluasi dilakukan dengan melihat hasil yang diperoleh dalam jangka waktu yang telah disepakati dan melibatkan peran aparat desa dan kader yang inovatif serta pihak Dinas Pertanian dengan demikian target lebih mudah terwujud.
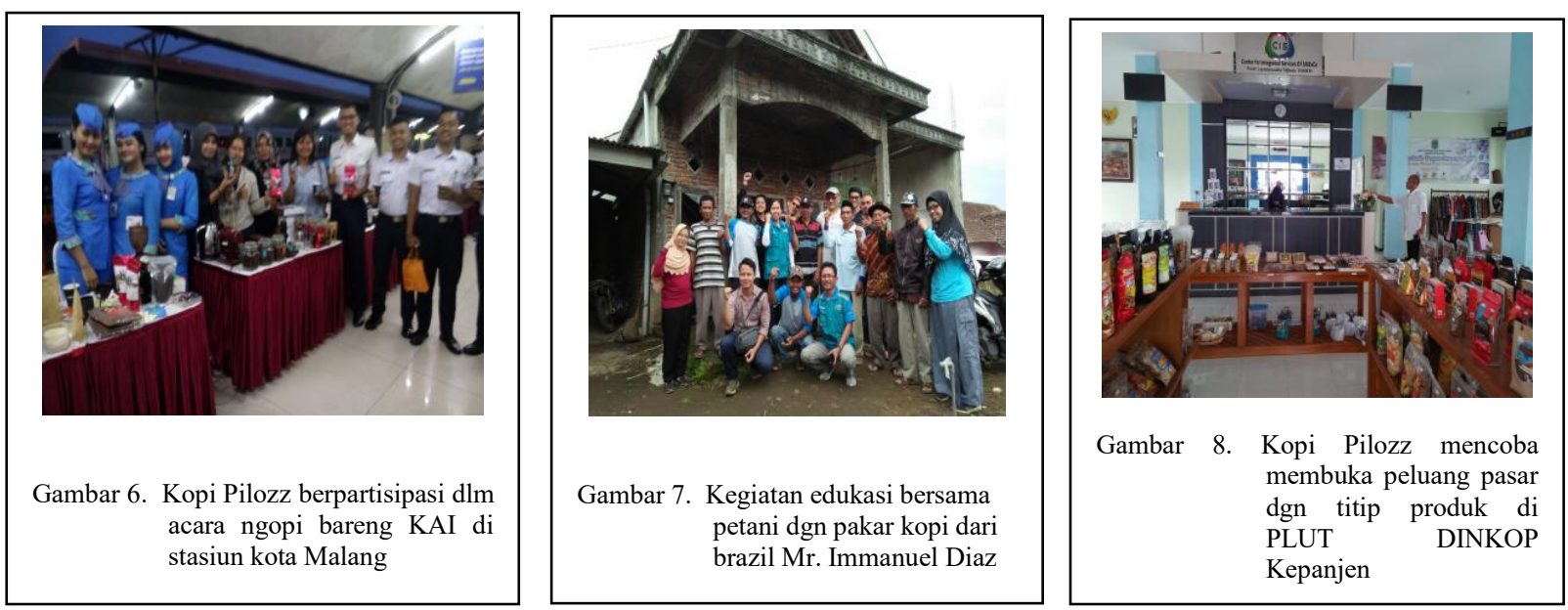

\section{DAFTAR PUSTAKA}

[1] Choiron, M. 2016. Penerapan GMP pada Penanganan Pasca Panen Kopi Rakyat untuk Menurunkan Okratoksin Produk Kopi (Studi Kasus di Sidomulyo, Jember). AGROINTEK, 4(2), 114120.http://infestasi.trunojoyo.ac.id/agrointek/article/ view/1363[21 Mei 2019].

[2] Santoso, B., 2016. Pendugaan Fungsi Keuntungan dan Skala Usaha Pada Usahatani Kopi Rakyat di Lampung. Jurnal Agro Ekonomi 6.1-2 (2016): 2941.,http://www.ejurnal.litbang.pertanian.go.id/index. php/jae/article/view/5210 [7 Mei 2019].

[3] Herawati, T, B. Utomo dan W. Dirjopranoto. 2009. Profil Petani Miskin Di Desa Hutan Dan Upaya Pemberdayaannya, http ://ntb.litbang.deptan.go.id/20 04/SP/profilpetani.doc [15 Nopember 2018].

[4] Soetrisno, L, 1997. Kemiskinan, Perempuan, Pemberdayaan. Kanisius. Yogyakarta.

[5] Sunyoto U., 1998. Pembangunan dan Pemberdayaan Masyarakat, Pustaka Pelajar. Yogyakarta.
[6] Candra, K. M., Laurensia, F., dan Santoso, F. 2011. Proses pengolahan kopi instan, kopi blending, dan kopi tubruk di Pusat Penelitian Kopi dan Kakao Indonesia Jenggawah-Jember. http://repository.wima.ac.id/406/2/Bab\%201.pdf. [18 Mei 2019].

[7] Karyadi, J. N. W., Lumbanbantu, J., dan Rahayoe, S. 2009. Pengaruh Suhu Dan Lama Penyangraian Terhadap Sifat Fisik-Mekanis Biji Kopi Robusta. Semina Nasional Perhimpunan Ahli Teknik Pertanian Mataram 2009, A217-A225. https://repository.ugm.ac.id/33122/[8 Mei 2019].

[8] Jayanti, N. K. D. A., Sastrawangsa, G., dan Suradarma, I. B., 2016. Pemanfaatan Teknologi Informasi Dalam Meningkatkan Nilai Jual Dan Pemasaran Bagi Ukm Kopi Bali. Ngayah: Majalah Aplikasi IPTEKS, http://jurnal.unmas.ac.id/index.php/ngayah/article/vi ew/686[17 Mei 2019]. 


\section{PENGHARGAAN}

Ucapan terimakasih disampaikan kepada Direktorat Riset dan Pengabdian Masyarakat, Direktorat Jenderal Penguatan Riset dan Pengembangan, Kementrian Riset, Teknologi, dan Pendidikan Tinggi, yang telah membiayai kegiatan pengabdian kepada masyarakat yang berjudul PKM kopi Pilozzdi Desa Bocek Kecamatan Karangploso Kabupaten Malang ini dapat disusun. Pelaksanaan kegiatan ini dibiayai oleh Direktorat Riset dan Pengabdian Masyarakat, Direktorat Jenderal Penguatan Riset dan Pengembangan, Kementrian Riset, Teknologi, dan Pendidikan Tinggi, sesuai dengan Kontrak Pengabdian Kepada Masyarakat: 111/SP2H/PPM/DRPM/2019, Tanggal 26 Maret 2019. 